\title{
O uso do jogo on-line como possibilidade de aprendizagem da Matemática
}

\author{
Max Lindoberto Castro Gonçalves - PPGENSIMAT - IM - UFRGS - \\ max_goncalves@yahoo.com.br
}

\begin{abstract}
Resumo. O presente artigo apresenta uma proposta de trabalho com jogos computadorizados em aulas de Matemática praticadas no ensino fundamental. Partimos de uma reflexão acerca da importância do uso de recursos tecnológicos como forma de desenvolver habilidades de resolução de problemas, recorrendo a noções clássicas sobre o papel do lúdico na formação humana e aos parâmetros que organizam o ensino dessa ciência na educação brasileira. A seguir, valendo-nos de um diagnóstico do estado atual da presença da informática no cotidiano da educação matemática, apresentamos duas propostas de trabalho com games a serem praticadas em turmas do sexto e do nono ano do ensino fundamental.
\end{abstract}

Palavras-chave: jogos on-line - Matemática - ensino fundamental

\section{The use of the online game as a possibility of learning of Mathematic}

\begin{abstract}
This article presents a proposal of work with computer games in Mathematic classes in elementary school. We started from analyzing the importance of the use of technological resources as a way of developing the ability of solving problems, using classical notions of the role of the playful in the human formation and the parameters which organize the teaching of this science in Brazilian Education. Following, relying on a diagnosis of the current state of the presence of informatics in the mathematics education day-by-day, we present two work proposals with games to be practiced in groups of sixth and ninth grade of elementary school.
\end{abstract}

Keywords: Online Games - Mathematic - Elementary School

\section{Introdução}

Ë senso comum que a Matemática deve desenvolver as habilidades de resolução de problemas. No entanto, apesar do consenso em torno dos objetivos que devem nortear o ensino dessa ciência, os caminhos adotados pela escola nem sempre se configuram eficientes. Os motivos vão do despreparo dos professores aos equívocos quanto às metodologias ou ao material didático utilizado. Um exemplo gritante dessa distorção está nos livros didáticos. Sabemos que os exercícios do tipo "siga o modelo" que encontramos nos mesmos não dão conta da exploração das referidas habilidades, pois não favorecem a criação de um ambiente onde o aluno deva criar estratégias próprias. Antes de tudo, são atividades de mera repetição, que condicionam comportamentos e anulam autonomia e criatividade. Da mesma forma, de nada adianta recorrer à tecnologia se o uso do computador, especificamente dos jogos on-line, entram na sala de aula através de metodologias que repetem a postura passiva dos alunos.

Com base no exposto, faz-se necessário mudarmos o ensino da Matemática se quisermos atingir o objetivo básico de levar o sujeito a construir suas próprias alternativas na solução dos problemas e isso envolve, a nosso ver, mudanças nos caminhos metodológicos tomados pelos professores, entre os quais e em especial, no uso adequado dos recursos tecnológicos hoje disponíveis.

Tal mudança está em sintonia não apenas com as expectativas dos alunos, que esperam por aulas mais dinâmicas e conectadas com o uso que já fazem da tecnologia 
em seu cotidiano, mas com as próprias diretrizes educacionais vigentes a partir do lançamento dos Parâmetros Curriculares Nacionais na década de 90. No volume 3 dos PCN, o item que trata da caracterização da área da Matemática apresenta, entre outros, o seguinte princípio norteador:

Recursos didáticos como jogos, livros, vídeos, calculadoras, computadores e outros materiais têm um papel importante no processo de ensino e aprendizagem. Contudo, eles precisam estar integrados a situações que levem ao exercício da análise e da reflexão, em última instância, a base da atividade matemática.(PCN, 1997, p. 20)

Como se vê, analisar e refletir não são apenas desdobramentos do ensino da Matemática, mas estão na raiz da sua presença no dia a dia dos indivíduos. $\mathrm{O}$ desenvolvimento dos recursos tecnológicos e o seu acesso cada vez mais democratizado na sociedade permitem ao professor ter à sua disposição aliados importantes para que a atividade matemática se faça de forma efetivamente analítica e reflexiva. Temos, então, aqui, a questão central que procuraremos desenvolver ao longo desse trabalho, ou seja, como usar os jogos on-line de forma a desenvolver as habilidades de análise e reflexão dos alunos.

Inicialmente, é preciso destacar que os jogos on-line se apresentam de forma absolutamente variada e de fácil acesso entre os jovens que hoje navegam na rede mundial de computadores, tendo em vista a popularização do acesso à internet, seja nas escolas ou através dos programas governamentais. Além disso, corrobora para a facilidade de inclusão dessa tecnologia nas aulas de Matemática, o grande número de sites que oferecem estes jogos gratuitamente. Um professor engajado na luta pela transformação de suas aulas em ambientes que efetivamente promovam o desenvolvimento do aluno, tem a sua disposição uma leque de jogos, basta saber como utilizá-los.

Por estas razões, queremos explorar aqui a utilização de jogos on-line, bem como oferecer uma seqüência didática para o trabalho com a Matemática no ensino fundamental. Para tal, partiremos de uma contextualização do uso dos jogos como estratégia de ensino na educação básica, uma realidade que se mostra ainda longe da ideal. A seguir, apresentaremos a descrição e a análise de dois jogos matemáticos disponíveis da rede, Number Karts e Senha, que, a nosso ver, são potencialmente adequados para um bom uso didático. Finalmente, apresentaremos duas sugestões de atividades, uma para cada game, a serem aplicadas em turmas de sexto e nono ano do ensino fundamental. Com o presente trabalho, pretendemos contribuir para a discussão que envolve o uso da tecnologia na educação matemática como forma de desenvolver habilidades nos alunos de modo a torná-los mais críticos e conscientes.

\section{O lugar no jogo no ensino da Matemática}

O jogo faz parte da formação do ser humano antes mesmo da cultura. Segundo Huizinga , no já clássico Homo Ludens:

(...)mesmo em suas formas mais simples, ao nível animal, o jogo é mais do que um fenômeno fisiológico ou um reflexo psicológico. Ultrapassa os limites da atividade puramente física ou biológica. É uma função significante, isto é, encerra um determinado sentido. No jogo existe alguma coisa "em jogo" que transcende as necessidades imediatas da vida e confere um sentido à ação. Todo jogo significa alguma coisa.(2008, p. 3-4) 
Essencialmente, toda atividade lúdica encerra um sentido, um conteúdo e, por isso, converte-se numa das necessidades humanas mais elementares. Jogar é criar suposições, apostar e lidar com um sentido permanentemente aberto, que só se completa em ação. Logo, para ser fundamentalmente jogo, precisa fugir a condicionamentos e automações. Nesse sentido, algumas características do jogo devem ser salientadas:

- a virtualidade;

- a liberdade que deve envolver o processo (não são dadas ordens a todo momento);

- a irrealidade do jogo.

A essência virtual do jogo reside no fato de que ele lida com elementos que se situam para além do concreto. No caso dos jogos on-line, essa virtualidade é dupla, pois envolve forma e conteúdo. Por outro lado, o jogo é essencialmente livre e desinteressado, determinando um intervalo na vida cotidiana e nas suas determinações imediatas e exigentes. Tanto que o prazer advindo de jogar reside nas oscilações entre sentimentos de desafio, prazer, dúvida, confirmação e frustração. Quando trazemos essas características para o uso dos jogos on-line em sala de aula, percebemos que, em muitos casos, elas são ignoradas e até mesmo negadas, anulando a própria natureza do lúdico.

Tal fato está na contramão das diretrizes que orientam hoje o ensino da Matemática. Sabemos que o uso da criatividade, da imaginação e da habilidade de resolver problemas é muito mais importante do que a capacidade de memorizar fórmulas ou de repetir mecanicamente métodos de resolução de problemas. Isso sem falar no desperdício de longo tempo para cálculos que as máquinas podem fazer. Por isso, sugerimos o jogo como uma estratégia de ensino que vai ao encontro dos novos paradigmas, onde é mais importante o "como" do que o "quanto", ou seja, importa mais saber quais estratégias utilizar para resolver um problema do que chegar a um resultado numérico, por exemplo.

Acreditamos que o lúdico evidenciado nos jogos é uma maneira de atingir alguns aspectos que propiciam a aprendizagem, uma vez que tornam as aulas mais prazerosas e interessantes para os alunos, fazendo com que o educando desenvolva estratégias próprias para atingir seus objetivos.

No entanto, reconhecemos que a mera presença dos jogos em sala de aula não garante a referida aprendizagem. Como já dissemos anteriormente, a metodologia empregada pelos professores é que pode garantir o caráter ao mesmo tempo libertário e instrutivo desse recurso tecnológico. Convém salientar que é imprescindível que o professor tenha clareza de quais objetivos pretende atingir com a utilização de determinado jogo e de que caminhos metodológicos irá se valer para atingi-los. Nesse sentido, concordamos com Lara (2005), quando diz:

Assim, se concebermos o ensino da Matemática como sendo um processo de repetição, treinamento e memorização, desenvolveremos um jogo apenas como sendo um outro tipo de exercício. Mas, se concebermos esse ensino como sendo um momento de descoberta, de criação e de experimentação, veremos o jogo não só como um instrumento de recreação, mas, principalmente, como um veículo para a construção do conhecimento.(p. 20)

A afirmação acima reflete a posição dos PCN em relação ao uso desse tipo de tecnologia pela escola. Está nos parâmetros:

Finalmente, um aspecto relevante nos jogos é o desafio genuíno que eles provocam no aluno, que gera interesse e prazer. Por 
isso, é importante que os jogos façam parte da cultura escolar, cabendo ao professor analisar e avaliar a potencialidade educativa dos diferentes jogos e o aspecto curricular que se deseja desenvolver. (1997, p. 49)

Infelizmente, a realidade escolar não espelha esse aspecto, ainda que os PCN insistam no uso das tecnologias da informação, apontando para a pertinência de utilizar softwares educacionais e para a necessidade de que os professores sejam capacitados para a escolha e aplicação destes softwares.

Apoiados na nossa experiência como professor de Matemática há dezoito anos no ensino médio em escola privada e nos últimos oito anos no ensino fundamental na rede pública municipal de Porto Alegre, percebemos a subutilização dos Laboratórios de Informática por parte do coletivo de professores, apesar desse recurso existir em todas as escolas municipais de ensino fundamental da capital e na totalidade das escolas do ensino privado, pioneiro na utilização de computadores na educação.

Partindo da realidade da escola onde trabalhamos atualmente e do uso da tecnologia na área da Matemática, percebemos que a escolha do recurso a ser utilizado no ambiente informatizado fica muito mais a critério do monitor da sala de informática do que da decisão do educador. Ocorrem então, a nosso ver, dois equívocos: primeiro, a ausência de um planejamento didático que torne a ida ao Laboratório parte das estratégias que levarão à construção de um conhecimento específico da área. Já o segundo, diz respeito ao fato de que as escolhas feitas pelo monitor também nem sempre são as mais pertinentes, tendo em vista que há o predomínio de acessos a jogos voltados mais para a competição em si do que para o desenvolvimento de estratégias.

Acreditamos que esta omissão do professor se explica, primeiramente, pela falta de formação específica voltada para a utilização deste recurso; considerando que ela só tem sido mais efetiva por parte dos cursos de licenciatura nos últimos anos. Além disso, ainda que os professores dominem a tecnologia, eles não estão atualizados quanto ao leque de opções de jogos on-line disponíveis e adequados ao uso na educação matemática. Delegam, assim, a tarefa ao monitor e abrem mão de aliados de peso na sedução do aluno para o universo da Matemática.

Por outro lado, não podemos deixar de mencionar outro fato, o de ser o Laboratório de Informática prioritariamente utilizado como um recurso para suprir a falta de professores, ficando os alunos lá acomodados para preencher o período, sem o menor planejamento. Tal atitude da escola explicita um duplo desperdício, pois subutiliza um espaço vital na formação dos sujeitos contemporâneos e ainda frustra os alunos, genuinamente interessados em trabalhar na Sala de Informática. Os educandos se desencantam uma vez que tem consciência da falta de planejamento e de um objetivo claro a ser atingido, sedimentando a idéia de que o uso dos computadores pela escola reduz-se apenas a uma forma de passar o tempo.

Tal desencontro entre as expectativas dos educandos e o que a escola oferece em termos de uso pedagógico da tecnologia, pode ser ratificado, por exemplo, pela pesquisa realizada por Figueiredo e Bittencourt (2005), a qual conclui que os alunos sentem prazer ao superar os obstáculos oferecidos pelos jogos, mas rejeitam aqueles cujo cunho é eminentemente didático. Eles querem ser desafiados e confessam que não jogam para adquirir conhecimento e sim para se divertir, pois acham os jogos educativos chatos. Então, o caminho é promover o cruzamento entre os dois objetivos, o do prazer e o pedagógico, através da ampliação e da diversificação do material oferecido, encontrando jogos que não tenham esta marca de jogo educativo, mas que se prestem a 
desenvolver as habilidades de análise e reflexão propostas na essência da educação matemática.

\section{Jogos e ensino: uma proposta}

A partir das considerações anteriormente feitas, queremos trazer aqui, como sugestão, duas propostas de jogos on-line para serem utilizados nas aulas de Matemática: o Number Karts, disponível em http://www.clickjogos.com/jogo/numberkarts.html e o Senha, disponível em http://www.jogueaqui.ig.com.br/jogosonline.php? jogo=mind, ambos gratuitos e de fácil acesso.

O jogo Number Karts, que recomendamos para turmas de sexto ano do ensino fundamental (antiga quinta série), pode ser jogado por dois alunos e é a simulação de uma corrida de dois carrinhos, um para cada jogador, em uma pista. O avanço dos carrinhos no trajeto a ser vencido depende da escolha, por parte do jogador, de uma entre três opções de quantidades de casas a serem avançadas, número esse que varia a cada nova rodada. As casas da pista são da cor amarela, verde e vermelha. Se, após a escolha do número de casas a serem avançadas, o carrinho parar em um intervalo amarelo, ali permanecerá até a próxima jogada; caso pare em uma casa verde, avançará o número de casas ali indicado; e, finalmente, caso venha a parar em uma intervalo vermelho, retornará o número de casas ali indicado. Assim, será vencedor o carrinho que cruzar primeiro a linha de chegada.

O jogo, porém, apresenta um incremento nessa estrutura simples. Como costuma acontecer em softwares desse tipo, ele permite que o usuário escolha entre três diferentes níveis de dificuldades. Em um primeiro nível, o número de casas a serem vencidas pelos carrinhos a cada jogada é dado através de três opções de forma direta, explícita. Porém, no nível dois, a escolha do número de casas para deslocamento deve ser feita realizando operações de adição ou subtração. Já no nível três, as sugestões do número de casas ocorrem através de operações de multiplicação e divisão. Logo, no caso dos níveis dois e três, antes de escolher quantas casas quer avançar, o aluno deve realizar as operações.

A escolha do jogo acima, que parte de uma estrutura simples, similar a vários outros jogos de tabuleiro, justifica-se pelo fato de que o aluno, além de retomar as quatro operações, terá de refletir sobre a quantidade de casas de deslocamento a serem escolhidas, considerando que nem sempre um número maior de casas significará um avanço maior na pista. Ao perceber a sutileza do jogo, o aluno passará a utilizar estratégias a cada jogada. Neste momento, estaremos atingindo o objetivo a que se propõe este trabalho: o aluno estará analisando, refletindo e criando estratégias a cada jogada.

A seguir, apresentamos uma sugestão de atividade, considerando a utilização do jogo acima apresentado nas aulas de Matemática. A partir da descrição feita acima, percebemos que o Number Karts pode ser bastante produtivo como atividade de revisão de operações com números naturais em uma turma de sexto ano do ensino fundamental. Considerando o uso do Laboratório de Informática pelo professor por um período de $2 \mathrm{~h} / \mathrm{a}$, uma turma de, aproximadamente, trinta alunos, poderia ser organizada em duplas. Acomodados diante do computador, seria solicitado, então, que os próprios alunos abrissem a página do jogo e que, junto com o professor, lessem as instruções fornecidas. Acreditamos que o envolvimento e a motivação para o desenvolvimento da atividade são reforçados pelo fato de o aluno ter, ele mesmo, que trilhar os caminhos de acesso ao game, ao invés de já encontrar o monitor "pronto" para iniciar a competição.

Dada a largada, os alunos jogariam duas rodadas no nível um, aquele que oferece as alternativas de avanços de casas diretamente, sem uso das operações 
matemáticas. O jogo, então, seria interrompido para que os alunos discutissem o que observaram até o momento em termos de estratégias usadas e dificuldades encontradas. O professor interferiria no sentido de levá-los a perceber que nem sempre escolher o maior número significava avançar mais na pista, pois poderiam cair em uma casa vermelha e ter que retornar. Os alunos, nesse momento, voltariam a praticar mais uma vez no nível um, prestando atenção nas estratégias que usariam para garantir um avanço, ao mesmo tempo, rápido e seguro.

A seguir, passariam para os níveis dois e três, onde além da estratégia a escolher, reside a operação matemática a ser resolvida, ficando três rodadas em cada um desses níveis. Para encerrar, solicitaríamos aos alunos que comentassem suas impressões do jogo, especialmente depois que passaram a utilizar uma estratégia definida, e que dificuldades tiveram quando apareceram as operações nos níveis dois e três.

Diante disto, a atividade seria considerada satisfatória se os alunos conseguissem perceber e aplicar a melhor estratégia para o jogo, além de realizar as operações oferecidas ou manifestar em quais tiveram dificuldades.

Nossa outra proposta envolve o game Senha, muito difundido nas décadas de setenta e oitenta em tabuleiros, mas aqui apresentado na forma on-line. O jogo consiste em conseguir acertar a ordem em que são dispostas quatro cores dentre as seis (existe também com oito opções) oferecidas de forma aleatória pelo programa. Lembremos que a probabilidade do jogador acertar as quatro cores é de uma em quinze $\left(C_{6}^{4}\right)$, mas a probabilidade de acertar as quatro cores e também a ordem em que deverão ser dispostas é de uma em trezentos e sessenta $\left(A_{6}^{4}\right)$. Arriscada a primeira sequência, o jogador recebe a informação de quantas (não quais) cores acertou e quantas (não quais) estão na posição correta. Com base nestas informações o jogador organiza sua ordem de cores para a próxima jogada, e assim sucessivamente, tendo ao todo dez jogadas para acertar a sequência correta de cores.

Como podemos perceber, o raciocínio combinatório está evidenciado neste jogo, o que justifica o fato de já ter sido foco de algumas pesquisas, como a de Santos (2007), por exemplo, que o utilizou como recurso para o ensino de Análise Combinatória no artigo "Explorando a Análise Combinatória no Jogo Senha". Portanto, o Senha, que indicamos para uso no nono ano do ensino fundamental (antiga oitava série) como atividade introdutória à construção dos conceitos combinatórios, também vem ao encontro de nossa proposta de uso de um game que leve o educando a analisar, refletir e criar estratégias para resolver o problema proposto pelo jogo.

Nesse sentido, como na atividade anterior, também pressupomos a utilização de 2h/a para o desenvolvimento da atividade, ainda considerando um grupo médio de trinta educandos. Acomodados no Laboratório de Informática, os alunos primeiramente receberiam as instruções do professor, tendo em vista que as fornecidas pelo próprio game não são muito claras. Nesse sentido, a orientação dada seria de que os alunos concebessem a tela como um tabuleiro convencional, esclarecendo que o papel do segundo jogador seria feito pelo computador.

Após as explicações iniciais, solicitaríamos que os alunos formassem duplas e jogassem uma partida cada, um de cada vez, e que, enquanto um jogasse, o outro observasse e anotasse o que teria feito diferente e por quê. Concluída esta primeira rodada de jogos, solicitaríamos que os alunos relatassem o que observaram enquanto sua dupla jogava. Como sabemos, provavelmente poucos alunos iriam se manifestar, mas, através da intermediação do professor, seria importante que todos refletissem a partir das seguintes questões: 
1. Se estão disponíveis seis cores e escolhemos quatro, qual o número máximo de cores erradas em cada jogada?

2. O que é mais difícil, acertar a escolha das cores ou a posição destas?

3. Se na primeira jogada acertarmos duas cores, qual a melhor maneira de descobrir as outras duas?

Após estes questionamentos, e outros que poderiam ser formulados, solicitaríamos que os alunos jogassem novamente, trabalhando em duplas e anotando porque tomaram determinadas decisões a cada passo. Posteriormente, retomaríamos, no grande grupo, estas anotações.

A atividade seria considerada satisfatória se o aluno conseguisse organizar de forma lógica a sua sequência de passos para o jogo e percebesse as noções primitivas de arranjo e permutação.

\section{Considerações finais}

A partir do exposto acima, concluímos que existem alternativas para um ensino da Matemática onde haja maior envolvimento do aluno e, conseqüentemente, resultados mais eficientes quanto ao desenvolvimento de suas habilidades de analisar e refletir. Mas, para isso, temos, primeiramente, que reavaliar quais são os conceitos que queremos desenvolver com nossos educandos e que recursos se mostram mais adequados para tal.

Há muito que tão somente quadro e giz não dão mais conta da ensinagem e que os alunos esperam por aulas mais dinâmicas e em sintonia com os avanços tecnológicos, com os quais já estão familiarizados. Logo, seria um contra-senso desperdiçar o recurso da informática, em especial os jogos on-line na educação matemática, visto o espaço disponível nas escolas anteriormente referido e a facilidade e o prazer que os alunos tem em utilizar esses recursos. Portanto, esperamos, com as duas propostas apresentadas, ter contribuído para despertar a busca por alternativas de metodologia de ensino da Matemática.

\section{Referências}

FIGUEIREDO, Cibele Z.; BITTENCOURT, João R. Jogos Computadorizados para Aprendizagem Matemática no Ensino Fundamental: Refletindo a partir dos Interesses dos Educandos. Novas tecnologias na Educação. Porto Alegre, maio, 2005, v.3, no. 1. Disponível em: http://seer.ufrgs.br/renote/article/viewFile/13802/7999. Acesso em: 12 out.2010.

HUIZINGA, Johan. Homo Ludens: o jogo como elemento da cultura. São Paulo: Perspectiva, 2008.

LARA, Isabel Cristina Machado de. Jogando com a Matemática na Educação Infantil e Séries Iniciais. São Paulo: Respel, 2005.

SANTOS, Rogério C. Explorando a Análise Combinatória no Jogo Senha. Revista do Professor de Matemática. No. 64, SBM, 2007.

SECRETARIA DE ENSINO FUNDAMENTAL. Parâmetros curriculares nacionais: matemática. Brasília: MEC/SEF,1997. 